\title{
Humanizing the Consumer through Neuro-Marketing Tool: A Paradigm Shift.
}

\author{
${ }^{1}$ Dr. Suheela Shabir, ${ }^{2}$ Dr.Norah Al Bishri, ${ }^{3}$ Dr. Zubair Amin \\ ${ }^{1,2}$ Assistant Professor, College of Business and Administration, Princess Nora Bint Abdul Rahman University. Riyadh, Saudi Arabia. \\ ${ }^{3}$ Department of Education, Government of Jammu and Kashmir.
}

\section{ABSTRACT :}

Neuroscientific techniques allow consumer researchers to understand the basic framework of psychological processes that drive consumer behavior, and get into their "black box" which is the consumer's mind. Each year, over 400 billion dollars is invested in advertising campaigns. Under the traditional marketing mindset, the testing of and predicting the effectiveness of these investments depend on consumers' willingness and competency to describe how they feel when they are exposed to an advertisement. Neuro marketing offers innovative methods for directly probing minds without requiring demanding cognitive or conscious participation. This paper discusses the increased use of neuro marketing techniques for the evaluation of customer preferences and decision-making processes is considered to be an advantage for customers and marketers simultaneously. The results indicate that neuro marketing is associated to have a high influence on consumer buying behavior, advertising, pricing, and distribution of products, branding and decision-making as marketing inputs. The research concludes with limitations and future scope of research in neuro marketing.

\section{KEYWORDS:}

consumer behavior, cognitive, neuro marketing, branding, advertising, Physiological

\section{INTRODUCTION:}

The study of behavior related to the choice, purchase, and use of goods and services have long attracted diverse collection of ideas and techniques, including those from psychology, economics, marketing, and increasingly, neuroscience. At the heart of all commercial and economic activities is the consumer, whose preferences and choices heavily influence a host of decisions and actions by entrepreneurs, firms, and governments [1].These choices range from weighty ones such as purchasing a home to routine ones such as grocery shopping. Scientifically, theories of consumer choice are foundational to a number of fields in the social and biological sciences [1필. In applied settings, governments and companies expend considerable sums to forecast individual-level and aggregate choices and to shape preferences [2]. The consumer decision journey historically involves having a large number of potential buying choices that enter the sales funnel at its widest end, which represents limited product knowledge and brand awareness. Consumers continue to move through this purchase funnel toward product knowledge, trial, and eventually attain brand loyalty at the funnel's very tip. This traditional customer journey funnel had been sold as the accepted view of consumer behavior. However, considering the evolution of buying experiences in recent years, the customer journey is much more complicated these days. It may not represent a straight line down an obvious funnel. The high volume of products and services available forces consumers to do multiple rounds of research before making a purchase.

The new technological advances achieved during the last decade allowed the scientific community to investigate and employ neurophysiological measures not only for research purposes but also for the study of human behavior in real and daily life situations. The aim of this paper is to understand how neuroscientific tools can be effectively employed to better understand the human behavior in real decision-making contexts. To do so, firstly, we will describe the historical development of neuro marketing and its main applications in assessing the sensory perceptions of some marketing and advertising stimuli. Then, we will describe the main neuroscientific tools available for such kind of investigations (e.g., measuring the cerebral electrical or hemodynamic activity, the eye movements, and the psychometric responses). Then the effectiveness of these tools will be discussed in the light of value addition that it makes to marketers. Furthermore, this paper will discuss the ethical considerations 
on the use of these tools for evaluating human behavior during decision-making tasks followed by future scope of research in this field.

Since the emergence of Neuro marketing field in 2002, its importance is consistently growing in terms of its application for companies, marketers and advertisers. This paper will concentrate on the clarification of human behavior by the use of neuro marketing and its benefits and drawbacks in the economic sector. There is certain evidence suggesting that the brain itself is the main mediator of human behavior, expressed emotions and decision-making processes [4]. Additionally, certain evidence shows that in the majority of the cases, people are unable to express their reasons for behavior or the reasons for preference of certain things, consciously or unconsciously [5]. With this in mind, the argumentation by Camerer,[6] Kenning[7], Hubert [8], Sanfey,[9], stating that neuro economics takes neural and physiological processes as the basis for the explanation of consumer behavior, seems justifiable. Although neuro marketing is not going to compensate for traditional approaches, there is high evidence that emerging tools such as FMRI (functional magnetic resonance imaging) will upgrade the productivity of marketing strategies[10] [11] [12]. Since branding and advertising are assumed to have relevant impact on consumer preferences for products, it is likely that neuro marketing could contribute and influence these consumer preferences by the application of neuro marketing techniques in a positive way [13] [14]

According to Ariely and Berns (15), the main purpose of marketing is to help create products that fit people. Under this assumption, marketing serves two main proposals. The first is to guide the design and presentation of products so that they become more compatible consumer preferences. The second is to facilitate the consumer decision process. One of the big questions that permeate society yet to be clarified is: what leads the consumer to make a choice for a specific brand or product over the other, based on the perceived costs and benefits $[16,17]$. Faced with this question and technological development of the last decades, an alternative to better understand consumer behaviour has gained strength against the traditional existing in the marketing field; neuro marketing. Stanton[18] consider neuro marketing as the use of neuroscience and physiological research techniques to gain new insights into consumers' behaviour, preferences, decision making, and other aspects of human cognition and behaviour related to marketing. The combination of the neuro and marketing terms implies the convergence of two fields of study, neuroscience and marketing. Plassmann[19] indicate that neuro marketing can be distinguished from consumer neuroscience by restricting the former to industry applications and the latter to academic research. Consumer neuroscience is thus a more rigorous version of neuro marketing, delivering findings that are embedded in theory [20].One can make a parallel in which neuro marketing is to marketing as neuropsychological is to psychology. While neuropsychology studies the relationship between the brain and the cognitive and physiological functions of the human being, neuro marketing promotes the value of inquiring about consumer behaviour from a physiological perspective [21]

The combination of cognitive neuroscience and marketing research has seen great advances in scientific production, examining a wide variety of phenomena related to market changes. Advances in neuro marketing techniques can offer a new perspective on the various processes involved in these exchanges, such as pricing policy and strategy, distribution channels, branding questions and other factors that influence consumer behavior[22]. In recent years, the application of neuroscientific techniques to the study of emotional and cognitive responses of consumers has been growing, and is seen as one of the main areas of studies on consumer behaviour for the future, and a great asset for companies to improve their communication with consumers [23]. This field becomes increasingly interesting to both researchers and the market, as it provides more reliable information than that obtained through traditional marketing methods such as consumer behaviour and the rationalisation of decision making [24.25].

According to Dinu [26], new consumer behaviour study techniques should contribute to decision making through the use of information to facilitate this process in order to identify the real reasons for the purchase that should cause a major upheaval in the companies, making these further focus their research on consumer behaviour. It means that the development of the collaboration between neuroscience and marketing researchers can help advance knowledge in several key areas, not only related to consumer decisions, but also on how we interact, relate, and behave in the present context of markets and organisations, being fundamental to the success of any market initiative [27].

In this context, the main objective of this paper is to familiarize the reader with the broad topic of neuro marketing and its use for the company as well as for the consumer. However, the primary goal is to evaluate upon the influence of neuro marketing tools on several marketing inputs, namely consumer buying behavior, advertising, pricing, new product development, communication, distribution of products, branding and decision-making. It is desired that the analysis of neuro marketing research results will provide us the information about customer's behavior and their preferences will be revealed. Marketing processes will be facilitated and that the analysis of neuro marketing research results will help to segment humans in such a way that individual differences in decision-making processes can be identified. It is expected that this study will contribute to the consolidation of existing knowledge and primarily suggest the main study opportunities existing in the neuro marketing field. 
This will assist in the development of understanding of how the consumer behaves in the face of various stimuli to which they are subjected to daily.

\section{THEORETICAL FRAMEWORK OF NEURO MARKETING}

There is a famous saying "marketing is no longer about the products that we make but about the stories we tell". The stories reaching the consumers through advertisements and soliciting must create an emotional chord between the product and the consumers. Traditionally marketers and advertisers have used different methods of advertisements and product development initiatives. This involves huge monetary inputs and time duration, which never got its way to people's memory bank and persuade their decision-making. Neuro marketing technique is the latest and advanced tool used by marketing researchers to study and understand the consumer behavior patterns. Neuro marketing uses innovative techniques in brain scanning to understand the nuances behind the psychological decision-making process of the customer. By Neuro marketing one can positively single out the element of an advertisement that creates a feel-good effect in the minds and memories of the customer. This can help with the selection and timing of visual and audio features for an effective advertisement. This will affirmatively help in the creation of brands, brand research and its effect on decision-making process of the customer

Marketing professionals use a wide range of techniques ranging from focus groups and interviews to market testing. Generally, the simplest technique to be used incurs the lowest cost, as in the case of focal groups. In a particular moment or subject matter that may be delicate or some kind of taboo before society, this emotional state causes the respondent to expresses a view that sometimes is not theirs, but a common view defined by society on an issue. Some responses however are expressed in a non-consistent manner with reality, with the intention of impressing the interviewer [28].These approaches can be combined with an emerging discipline, neuro marketing, and thereby bring better results of the role and functioning of the brain during the decision-making process[29].

According to Fortunato[30], neuro marketing can be defined as a technique of neuroscience that identifies the cortical regions responsible for consumer behaviour, and also as a research tool for observing the reactions of the brain during sustained market stimulus by the consumer. Neuro marketing is an interdisciplinary field that aims to understand consumer behaviour, studying the brain through the use of various techniques, such as neuroimaging. The research aims to measure the impact on an individual market stimuli and thus provide new ways to understand how the consumer stores, comprises, processes and uses the wide range of information which is received daily [31]. According to Vlăsceanu [24], through neuro marketing it is possible to find out how the consumer behaves and makes decisions by accessing unconscious thoughts, emotions, feelings and desires that activate the buying decision. One can thus understand how the unconscious influences the buying decision and its relation to the marketing of products. In addition, it is hoped that a better understanding of the cognitive mechanisms of the brain through new technologies, has the potential to explain many questions that marketers face today. Consequently, efforts aimed at neuro marketing can help understand the types of complex purchasing behavior[30]. The degree of intensity of an experience directly influences the emotional engagement that we have about it, that is, the higher the intensity, the more consumers tend to engage on a particular experience, and this stimulation can influence at the time of purchase decision a specific product or service. A high degree of emotional engagement with an understanding of the presented stimulus may indicate intent to purchase[24]

According to Reimann [32], consumer neuroscience identifies several areas of the brain as being important for research. The first is the striatum, which consists of several subareas, the most important being the putamen, caudate nucleus and nucleus accumbens. According to studies, the striatum is the area where social factors have greater influence, and are directly linked to the purchasing decision, resuming preference for products and also making the relation of expectation and reward of previous purchases [33]

\section{TECHNIQUES OF NEURO MARKETING}

Some of the main techniques used in research related to neuro marketing are:

\section{Eye Tracking}

Eye tracking is a technique that measures where the person is looking, the time spent looking at one point, and where the individual has set their vision for longer, that is, where they had more attention. Through this technique, it is possible to identify the focus of consumer attention. As a disadvantage, the fact can be mentioned that this technique cannot capture stimuli related to the emotions and the areas activated by the individual during the search. Usually, eye tracking is used with other techniques in a complementary manner, and it has gained a lot of attention because of the great visual pollution we experience in the world, enabling researchers to identify the main focus of the research participant, and thus achieve better results with visual campaigns[34]. 


\section{EEG}

EEG is a technique in which electrodes are placed on the scalp of the individual to measure brain waves associated with various stimuli. It is less invasive and less expensive than other techniques and in addition, provides excellent performance in the assessment of emotional styles, meaning an excellent temporal resolution (millisecond changes in brain activity [35]. Being less sensitive to motion, EEG can be used in most experiments that require action by the participant, for example, experiments in supermarkets. In use, at least two points on the scalp must be set since the device takes reference points in space where these reference electrodes will be positioned. As a disadvantage, the fact that it is only effective in identifying most superficial electrical signals can be observed [36]

\section{fMRI}

Functional Magnetic Resonance Imaging is a neuroimaging technique that measures the amount of deoxygenated hemoglobin and, to Vecchiato [37] it is a technique which returns a sequence of well refined images of cerebral activity by measuring the level of oxygen within the cerebral blood flow. The technique is characterised by a high spatial resolution, hence capable of detecting activations also in deep brain structures.

\section{MEG}

The Magneto Encephalography is a non-invasive procedure to investigate neural activity. MEG directly measures the magnetic field created by the neural activity. This is in contrast to the EEG that conducts voltage fluctuations. The spatial and temporal intensity of brain activity among the different regions of the brain can be measured by MEG [38]. MEG offers increased spatial resolution, but the advantage is offset by its high cost [39].

\section{PET}

$\mathrm{PET}$, as with $\mathrm{FMRI}$, is a spatial imaging technique, but uses radioactive particles (positrons) that must flow through the body of the person, so that when activation in the brain occurs it is possible to identify the part of the stimulated brain, since the substance causes a reaction. This technique is considered invasive and expensive, which ultimately decrease the amount of studies that use it [40].

\section{Galvanic Skin Response.}

GSR is a technique that allows to assess states associated with emotion, cognition and attention [41] through electrodes attached to the fingers of the person that are sensitive to the change of local skin conductance due to activation of sweat [42]. Furthermore, GSR boost results and possibilities of use, e.g. how to relate emotions to good or bad feelings about a particular stimulus [43].

\section{THE ADDED VALUE OF NEURO SCIENCE TECHNIQUES:}

Advances in neuroimaging technology have led to an explosion in the number of research studies studying the living human brain, thereby developing the understanding of its structures and functions. With the explosion of impressive images from brain scans in both scientific and popular media, researchers from other fields in the social and behavioral sciences naturally become interested in the application of neuroimaging to their own research. The possibility to "get inside the heads" of customers has aroused an increase of interest in commercial enterprises for discovering the real needs of them and proposing the products or services that meet their specific desires and needs. But it is very important to highlight that, with neuro marketing techniques, companies have "just" the opportunity to better understand the consumer behavior and which are the processes underlying the decision-making process. Accordingly, this does not constitute the "buy button" to induce to buy products or services which companies promote.

With the help of advanced techniques of neurology, which are applied in the field of consumer neuroscience, a more direct view into the "black box" of a consumer should be possible. Consumer neuroscience should not be perceived as a challenge to traditional consumer research but constitutes a complementing advancement for further investigation of specific decision-making behavior; as mentioned above, it could be defined as the third dimension of it (after the qualitative and the quantitative marketing research). In such a scenario, brain imaging techniques, applied to human decision -making mechanisms, could be adopted to corroborate results obtained by traditional techniques.

In addition, we know from cognitive psychology that emotions too play an important role in memory processes: emotions can help us learn and remember [44]. Consumers are no longer considered completely rational because emotion and unconscious and automatic processes play a central role in generating behavior $[45,46]$. Therefore, these previous investigations showed that humans are not perfectly rational in making decisions. Therefore, the challenge lies on how to use the neuroscientific tools to discover the brain or physiological instinctive reactions to take into account their effects and to define the best strategies to reach better the consumer needs. In such a way, neuro marketing is an exciting promise for marketing evolution in the future and at present. 


\section{EFFECT OF NEURO MARKETING TOOLS ON MARKETING INPUTS}

The qualitative research technique neuro marketing - the implementation of neuroscience techniques to marketing - delivers enormous benefits compared to traditional marketing approaches $[47,48]$. The following relevant marketing tools will be considered in further detail and while it will be evaluated if neuro marketing techniques turn out to be useful in regard to consumer behavior.

\section{Neuro marketing on Consumer Buying Behavior}

The increasing number of products in the market makes the in-depth analysis of consumer buying behaviour highly desirable and advantageous $[49,50]$. The human brain conceals information of true desires and needs that influences buying decisions. Any knowledge of consumer decision making negates the cost of neuro marketing in comparison to the information delivered [15].

\section{Neuro marketing on Advertising}

The topic of advertisement and product presentation to consumers on the market are becoming increasingly relevant. Since the effects of advertising are not very well understood yet, neuro marketing and specifically neuroimaging techniques are considered to be an exiting and helpful instrument for marketers[15]. A recent study by Kenning and Linzmajer [51] elaborated upon the attractiveness of an advertisement and its correlated activation of brain areas. These brain regions were not activated when a less attractive advertisement was presented. This indicates that by making use of neuromarketing techniques, it is possible to find out if an advertisement is perceived to be attractive or not, and therewith figure out its effectiveness.

\section{Neuro marketing on Pricing}

The price of the product is an important factor that can potentially influence a customer purchasing decisions [52]. An important aspect of purchasing decision is fixing the ideal price for a service or product [53]. Fixing the price of a product and its association with purchase making decision of a customer is the trickiest part in marketing [54,55]. Neuro marketing can help the marketers to find the amount fixed for a product or a service on the mind of the customers. This will enable the marketers to adjust the prices of the product accordingly. Appropriate brain scanning techniques can be used to find regions of the brain activated by pain or happiness.

\section{Neuro marketing on New Product Development}

Neuro marketing tools are considered more appropriate for analyzing the product experience and not the conception and development of a new product [15]. Since no valid inputs can be obtained for the development of new product alternate methods can be used. In contrary, some studies also suggest that the internal information disclosed form fMRI scan data could be used for pretesting and development of new products [56]. Along with neuro marketing, SWOT analysis (Strengths, Weaknesses, Opportunities and Threats) can also be used for new product development.

\section{Neuro marketing on Communication}

Verbal communication expressed by the consumer will not be influenced by neuro marketing measurements since logically it can be analysed by the conventional methods of market research. Body language and facial expressions is analysed by outside reflex neuro marketing techniques [57]. However, the most accurate is the inside reflex measurements such as fMRI or EEG. Hence neuro marketing techniques will not be of great use in communication and scarce or no available literature is available in this regard.

\section{Neuro marketing on Distribution of Products}

Neuro marketing techniques can be used to make efficient distribution, arrangement and display of products in the shelves and racks of supermarkets. Neuro marketing techniques can be used to identify the ideal and effective arrangement pattern of products for attracting customers attention [58]. An important case of decision making is the top-shelf example. Products on the top shelves of the stores are more evaluated by the customers [59]. Products in the top shelves usually get more attraction from the customers [60]. Eye tracking and caps attached with EEG on customers head performing shopping can be used for studying the behaviour of shoppers [61]. Online shops can also be analysed by this method [62].

\section{Neuro marketing on Decision-Making}

Decision making in neuro marketing has five different stages. This include: identifying the problem, weighing the possible choices, decision after evaluation of the available choices, considering the possible consequences of decisions, learning for the future from decision making process [63]. The decision-making process analysed by fMRI neuro marketing technique is a culmination of emotions [64]. The decision-making process analysed by $\mathrm{fMRI}$ and EEG shows the involvement of ventromedial prefrontal cortex and striatum brain regions [65]. The consumer decision making process can also be manipulated to a certain extent $[66,67]$.

Neuro marketing on Branding:Customers normally prefer to attach loyalty to their preferred brands. Brands usually create emotional attachment and bonding that influence customer decisions [68]. This shows the importance of brand attachment and 


\section{Humanizing the Consumer through Neuro-Marketing Tool : A Paradigm Shift.}

the marketers should rightly use the opportunity. fMRI studies have shown increased brain activity in preferred brands than common brands $[69,70,71-73]$. Brands have created an intuitive and hidden apprehension that have an effect upon the decisionmaking process on a product [70]. Table 2 shows the successful use of neuro marketing strategies by the successful brands.

\section{Product Design}

Product design and presentation is important feature of marketing and market research Hence the product design and presentation aspect should be given sufficient attention to minute details. Neuro marketing tools like fMRI and EEG can help in better design of products [49]. Since the entire process takes place subconsciously in the brain it is highly reliable. The nucleus accumbens and ventromedial pre-frontal cortex region of the brain are associated with the process of decision making [74].

\section{NEURO MARKETING-ETHICAL OR UNETHICAL.}

The ethics of neuro marketing is an issue. Researchers should be aware and careful with ethical aspects when using brain scans and neuroscience advances to understand consumers' decisions. Of course, the use of scientific technology to promote commercial interest is not inherently problematic. However, the use of technology that tests the inner workings of the human brain, especially beyond what can be disclosed in traditional behavioral tests, raises significant ethical problems. These problems fall into two main categories: (1) protection of different parties that may be harmed or exploited by neuro marketing and (2) consumer autonomy protection [75]. Whether neuro marketing is just a benign method to help companies better understand customers' true desires while giving customers the power to influence companies should be addressed, as well as determining whether this method is a way of unconsciously suggesting the purchase of an otherwise unwanted item [76]. Moreover, neuro marketing by companies producing tobacco, alcohol, junk food, or quick food might be harmful to public health [77]. This also raises significant ethical problems for children and adults $[78,79]$. The protection of vulnerable populations is also part of the neuro marketing concerns $[80,81,82,83,84]$. Murphy et al. [85] suggested the need to regulate the use of neuro marketing techniques on children and other vulnerable groups, such as people with neurological diseases or pathological disorders, people sensitive to advertisements, and legally protected groups. 
Humanizing the Consumer through Neuro-Marketing Tool : A Paradigm Shift.

\begin{tabular}{|c|c|c|}
\hline Company & Industry & Purpose of Neuromarketing \\
\hline GMTV & Television & $\begin{array}{c}\text { Conduct a study to teach advertisers how viewer's brains act during } \\
\text { morning hours. }\end{array}$ \\
\hline VIACOM & Media & Study reactions to advertising. \\
\hline HAKUHODO & Advertising & $\begin{array}{l}\text { Observe responses to products, brands, advertising and video } \\
\text { content. }\end{array}$ \\
\hline PHD & Media Planning & Measure the relative effectiveness of advertising. \\
\hline Martin Lindstrom (Neurosense) & Author & $\begin{array}{l}\text { Neurosense designed and analyzed all the fMRI studies used for } \\
\text { Lindstrom's book research. }\end{array}$ \\
\hline Yahoo & Media & Study consumer's reaction to a television commercial. \\
\hline Hyundai & Automotive & Study consumer's reaction when viewing a sport's car. \\
\hline Microsoft & Technology $\backslash$ software & $\begin{array}{l}\text { Understanding consumer's interaction with computers including } \\
\text { their feelings of surprise, satisfaction and frustration. }\end{array}$ \\
\hline Ebay & Online auctions & Adopted ad campaign on the basis of neuromarketing research. \\
\hline Frito-Lay & Food & $\begin{array}{l}\text { Adjusted commercials, products and packaging on the basis of } \\
\text { neuromarketing based research. }\end{array}$ \\
\hline $\begin{array}{l}\text { Neurofocus (Conducted } \\
\text { neuromarketing research for among } \\
\text { others Google, Chevron and Walt } \\
\text { Disney company) }\end{array}$ & Neuromarketing research & Consulting based neuromarketing research \\
\hline The weather channel & Television & Study viewers reactions to promotions \\
\hline Daimler Automotive & Automotive & Study consumers reaction to car headlight characteristics \\
\hline Pepsico & Food & idea for single-serve packaging and corresponding ad campaign \\
\hline Porsche & Automotive & Consumer response to advertisement \\
\hline Facebook & Social Networking & frequently a page should post, how to plan out an ad campaign \\
\hline Coca Cola & Food & Effective advertisement of product \\
\hline PayPal & Money transfer & Advertisement emphasising speed and convenience \\
\hline Volvo & Automotive & Study related to car designing. \\
\hline Microsoft & Software & $\begin{array}{l}\text { Eye tracking and EEG measures to analyse the brain's response to the } \\
\text { various content, aesthetics and web design combinations }\end{array}$ \\
\hline Budweiser & Food & Study positive emotional response in advertisement \\
\hline
\end{tabular}

Table : Some prominent companies that use neuro marketing and their purpose of Neuromarketing Neuro marketing would then represent a major threat to the autonomy of consumers because it would remove their defensive mechanisms [86, 87, 88, 89,].

\section{METHODOLOGY}

This study was developed through an integrative literature review, which is a rather useful method in integrating and analyzing research results on emerging issues, collecting and analyzing the state of the literature relating to the subject, and identifying challenges to the development of future studies [90]. The literature review is a common method to investigate completely different approaches to a topic in study, which is expected to have as a result a good use of the proposed classification method, as well as the use of analysis results as a stimulus for further research on the subject [91]

\section{ANALYSIS OF THE RESULTS}

It has been observed that in recent years, neuro marketing has increased its representation in several areas of academic research demonstrating that it is a science with applicability in various areas of study, and development potential for better understanding of consumer behavior and of the variables that influence the decision to follow certain stimulus. Furthermore, the major part of studies is qualitative in nature, and has great heterogeneity in the methods and procedures used. This corroborates the statement of Solnais [92] that neuroscience consumer studies are heterogeneous, and diversity of procedures end up becoming difficult to generalise. Venkatraman[93] estimate that due to the currently available technology, consumer 
neuroscience can be used in conjunction with traditional methods of marketing, being possible to generalise the results in order to arrive at representative values of the entire population.

Ohme and Matukin[94] conducted a study in order to verify that neurophysiological techniques can help in understanding the subconscious consumer reactions to new product advertisements. A combination of traditional marketing with neuro marketing tools was used, which was initiated by a survey in which consumers should express their assessment of what part of an advertisement drew more attention to them. After this, through EEG, the subconscious response of this person to the same question in relation to the advertisement was verified. When making the comparison between the two results, the authors found that the answer provided by the subconscious differs from the answer given by the person at the beginning of the research. In addition, Ohme and Matukin[94] identified at what moment the advertisement aroused more attention and also that the combination of sound and image were fundamental to obtain a favourable result in the creation of a positive memory in the consumer. Another important factor, in addition to understanding how the consumer will receive an advertisement of new products, is to identify how the strength of the brand can influence the consumer's decision.

In the study by Khushaba [95], the authors observed that the synchronisation of the brain channel appears as an interesting tool for understanding how the variation of brain activity influences decision making and also how it affects the subjective preference for a product or service. Using more than one neuromarketing tool to obtain more conclusive results, a qualitative study was focused on understanding how gender differences affect the observation of television commercials. This study used three neuroscience tools: EEG, GSR and heart rate. It can be seen that the major difference between the genders occurs at the time they observed perfume television commercials, related to appreciation and spontaneous memories, both being higher responses in women.

With the growing importance of studies about neuro marketing and how it relates to the identification of the mannerisms of consumers and also how they make decisions, some literature reviews have been made on the subject, both focusing on methods, techniques and limitations, and the potential that neuroscience has for a given area of study. Consumer neuroscience begins to show its potential for several areas of work, including being presented as one of the possible templates for future understanding of consumer behaviour, indicating that professionals from diverse backgrounds, including biomedical engineers, must heed the opportunities that will appear in this field [96]

Furthermore, another subject, compulsive shopping, is also a common field in neurology and neuroscience of the consumer. Both can benefit from advances in research techniques, since the confidence of research in the medical context lacks empirical evidence of behaviour, something that consumer neuroscience can provide, provided the research techniques comply with the ethical questions about the methods used.

One of the main points discussed in relation to neuro marketing and neuroscience are ethical issues and free decisionmaking. Both are carefully observed by scholars in the field, including having the development and dissemination of a code of ethics as one of the main points to be resolved to further boost research. Ethics are also discussed in the professional context, since some companies use neuro marketing techniques and do not disclose their results, making the transparency and effectiveness of their methods to be questioned $[97,98,99]$

\section{LIMITATIONS AND FUTURE SCOPE OF RESEARCH}

The time aspect restricts the dimension of the study, This resulted in researching the already available data which enormously limits the possibility to actually research the influence of neuro marketing when applied to a human being. An empirical research where several human beings are being confronted with products and fMRI or EEG measurements are executed would increase the validity of the study. The research of neuro marketing is still in its infancy stage and it is advised that the human behavior research in all directions should definitely be continued. Furthermore, research in context of ethical issues of neuro marketing needs to be encouraged.

\section{CONCLUSION}

Neuro marketing offers exciting opportunities and provides new avenues to explore in the field of marketing. It highlights the importance of neuro marketing tools to better understand consumer behavior, and they generate more effective results when combined with the traditional marketing research techniques for providing more complete information in relation to consumers' decision-making. This paper attempts to identify the real potential for predictions about consumer behavior, distinguishing what can and what cannot be identified through the techniques of applied neuroscience. The development of ethical aspects and research protocols need to be better worked to ensure respect of consumer rights with regard to the invasion of privacy, free choice and scientific ethics. Hence, the paper has demonstrated the potential of neuro marketing to be recognized as a science and this field has to go a long way and cross several hurdles before it can emerge as a prominent tool in the field of market research. 


\section{REFERENCES}

1) Deaton A, Muellbauer J. Economics and Consumer Behavior. 1980 [Google Scholar].

2) Bettman JR. Information Processing Models of Consumer Behavior. J. Mark. Res. 1970;7:370-376. [Google Scholar].

3) Krebs JR, Davies NB. Behavioural Ecology: An Evolutionary Approach. 1997 [Google Scholar]

4) Murphy, E. R., Illes, J., \& Reiner, P. B. (2008). Neuroethics of neuromarketing. Journal of Consumer Behaviour, 7(4-5), 293- 302.

5) Vecchiato, G., Astolfi, L., De Vico Fallani, F., Toppi, J., Aloise, F., Bez, F., \& Babiloni, F. (2011). On the use of EEG or MEG brain imaging tools in neuromarketing research. Computational intelligence and neuroscience, 2011, 3.

6) Camerer, C., Loewenstein, G., \& Prelec, D. (2005). Neuroeconomics: How neuroscience can inform economics. Journal of economic Literature, 9-64.

7) Kenning, P., \& Plassmann, H. (2005). NeuroEconomics: An overview from an economic perspective. Brain Research Bulletin, 67(5), 343-354.

8) Hubert, M., \& Kenning, P. (2008). A current overview of consumer neuroscience. Journal of Consumer Behaviour, 7(45), 272-292.

9) Sanfey, A. G., Loewenstein, G., McClure, S. M., \& Cohen, J. D. (2006). Neuroeconomics: cross-currents in research on decision-making. Trends in cognitive sciences, 10(3), 108-116. 14

10) Keller, K. L. (2008). Strategic brand management: building, measuring, and man- aging brand equity (3 rd ed.). Upper Saddle River, NJ: Pearson/Prentice Hall.

11) Venkatraman, V., Clithero, J. A., Fitzsimons, G. J., \& Huettel, S. A. (2012). New scanner data for brand marketers: How neuroscience can help better understand differences in brand preferences. Journal of Consumer Psychology, 22(1), 143153.

12) Adolphs, R., Tranel, D., Koenigs, M., \& Damasio, A. (2005). Preferring one taste over another without recognizing either. Nature Reviews Neuroscience, 8(7), 860-861.

13) Bruce, A. S., Bruce, J. M., Black, W. R., Lepping, R. J., Henry, J. M., Cherry, J. B. C., \& Savage, C. R. (2014). Branding and a 12 child's brain: an fMRI study of neural responses to logos. Social cognitive and affective neuroscience, 9(1), $118-122$.

14) Esch, F. R., Möll, T., Elger, C. E., Neuhaus, C., \& Weber, B. (2008). Wirkung von Markenemotionen: Neuromarketing als neuer verhaltenswissenschaftlicher Zugang. Marketing ZFP, 30(2), 111-129.

15) Ariely, D. and Berns, G.S. (2010) 'Neuromarketing: the hope and hype of neuroimaging in business', Nature Reviews Neuroscience, Vol. 11, No. 4, pp.284-292, doi:10.1038/nrn2795

16) Hsu, M. and Yoon, C. (2015) 'The neuroscience of consumer choice', Current Opinion in Behavioral Sciences, Vol. 5, No. 5, pp.116-121, doi:10.1016/j.cobeha.2015.09.005

17) Solnais, C., Perez, J.A., Fernandez, J.S. and Abela, J.A. (2013) 'The contribution of neuroscience to consumer research: a conceptual framework and empirical review', Journal of Economic Psychology, Vol. 36, No. 6, pp.68-81, doi:10.1016/j.joep.2013.02.011.

18) Stanton, S.J., Sinnott-Armstrong, W. and Huettel, S.A. (2016) 'Neuromarketing: ethical implications of its use and potential misuse', Journal of Business Ethics, pp.1-13 [online] https://doi.org/10.1007/s10551-016-3059-0.

19) Plassmann, H., Ramsoy, T.Z. and Milosavljevic, M. (2012) 'Branding the brain: a critical review and outlook', Journal of Consumer Psychology, Vol. 22, No. 1, pp.18-36, doi:10.1016/ j.jcps.2011.11.010.

20) Agarwal, S. and Dutta, T. (2015) 'Neuromarketing and consumer neuroscience: current understanding and the way forward', Decision, Vol. 42, No. 4, pp.457-462, doi:10.1007/ s40622-015-0113-1.

21) Morin, C. (2011) 'Neuromarketing: the new science of consumer behavior', Society, Vol. 48, No. 2, pp.131-135, doi:10.1007/s12115-010-9408-1.

22) Senior, C. and Lee, N. (2008) 'A manifesto for neuromarketing science', Journal of Consumer Behaviour, Vol. 271, No. 10, pp.263-271, doi:10.1002/cb.250.

23) Murphy, E., Illes, J. and Reiner, P. (2008) 'Neuroethics of neuromarketing', Journal of Consumer Behaviour, Vol. 302, No. 10, pp.293-302, doi:10.1002/cb.252.

24) Vlăsceanu, S. (2014a) 'Neuromarketing and evaluation of cognitive and emotional responses of consumers to marketing stimuli', Procedia - Social and Behavioral Sciences, Vol. 127, pp.753-757, doi:10.1016/j.sbspro.2014.03.349.

25) Vlăsceanu, S. (2014b) 'New directions in understanding the decision-making process: neuroeconomics and neuromarketing', Procedia - Social and Behavioral Sciences, Vol. 127, pp.758-762, doi:10.1016/j.sbspro.2014.03.350.

26) Dinu, G., Tanase, A.C., Dinu, L. and Tanase, F.D. (2010) 'The new techniques for handling consumer behaviour', Annals of DAAAM \& Proceedings, Vol. 21, No. 1, p.1115. 
27) Lee, N., Broderick, A.J. and Chamberlain, L. (2007) 'What is "neuromarketing"? A discussion and agenda for future research', International Journal of Psychophysiology, Vol. 63, No. 2, pp.199-204, doi:10.1016/j.ijpsycho.2006.03.007.

28) Hubert, M. and Kenning, P. (2008) 'A current overview of consumer neuroscience', Journal of Consumer Behaviour, Vol. 292, No. 10, pp.272-292, doi:10.1002/cb.251.

29) Ohme, R. and Matukin, M. (2012) 'A small frog that makes a big difference: brain wave testing of TV advertisements', IEEE Pulse, Vol. 3, No. 3, pp.28-33, doi:10.1109/MPUL.2012.2189169.

30) Fortunato, V.C.R., Giraldi, J.M.E. and Oliveira, J.H.C. (2014) 'A review of studies on neuromarketing: practical results, techniques, contributions and limitations', Journal of Management Research, Vol. 6, No. 2, pp.201-220, doi:10.5296/jmr.v6i2.5446.

31) Bercea, M.D. (2013) Quantitative Versus Qualitative in Neuromarketing Research, MPRA Paper No. 44134, pp.1-12, Munich [online] https://mpra.ub.uni-muenchen.de/44134/.

32) Reimann, M., Schilke, O., Weber, B., Neuhaus, C. and Zaichkowsky, J. (2011) 'Functional magnetic resonance imaging in consumer research: a review and application', Psychology \& Marketing, Vol. 28, No. 6, pp.608-637, doi:10.1002/mar.20403.

33) Knutson, B., Rick, S., Wimmer, G.E., Prelec, D. and Loewenstein, G. (2007) 'Neural predictors of purchases', Neuron, Vol. 53, No. 1, pp.147-156, doi:10.1016/j.neuron.2006.11.010.

34) Perrachione, T.K. and Perrachione, J.R. (2008) 'Brains and brands: developing mutually informative research in neuroscience and marketing', Journal of Consumer Behaviour, Vol. 318, No. 10, pp.303-318.

35) Stanton, S.J., Sinnott-Armstrong, W. and Huettel, S.A. (2016) 'Neuromarketing: ethical implications of its use and potential misuse', Journal of Business Ethics, pp.1-13 [online] https://doi.org/10.1007/s10551-016-3059-0.

36) Vecchiato, G., Astolfi, L., Fallani, F.V., Toppi, J., Aloise, F., Bez, F., Wei, D., Kong, W., Dai, J., Cincotti, F., Mattia, D. and Babiloni, F. (2011) 'On the use of EEG or MEG brain imaging tools in neuromarketing research', Computational Intelligence and Neuroscience, Vol. 2011, p.643489 [online] http://dx.doi.org/10.1155/2011/643489.

37) Vecchiato, G., Maglione, A.G., Cherubino, P., Wasikowska, B., Wawrzyniak, A., Latuszynska, A., Latuszynska, M., Nermend, K., Graziani, I., Leucci, M.R., Trettel, A. and Babiloni, F. (2014) 'Neurophysiological tools to investigate consumer's gender differences during the observation of TV commercials', Computational and Mathematical Methods in Medicine, Vol. 2014, No. 1, p.912981, doi:10.1155/2014/912981.

38) Miller M, Bentsen T, Clendenning DD, Harris S, Speert D (2008) Brain facts: A primer on the brain and nervous system, (6th edn). Society for Neuroscience, Washington.

39) Morin C (2011) Neuromarketing: The new science of consumer behaviour. Society 48(2): 131-135.

40) Tovino, S.A. (2007) 'Imaging body structure and mapping brain function: a historical approach', American Journal of Law \& Medicine, Vol. 33, Nos. 2-3, pp.193-228.

41) Vecchiato, G., Astolfi, L., Fallani, F.V., Cincotti, F., Mattia, D., Salinari, S., Soranzo, R. and Babiloni, F. (2010) 'Changes in brain activity during the observation of TV commercials by using EEG, GSR and HR measurements', Brain Topography, Vol. 23, No. 2, pp.165-179, doi:10.1007/s10548-009-0127-0.

42) Fontanella, L., Ippoliti, L. and Merla, A. (2012) 'Multiresolution Karhunen Loéve analysis of galvanic skin response for psycho-physiological studies', Metrika, Vol. 75, No. 3, pp.287-309, doi:10.1007/s00184-010-0327-3.

43) Gakhal, B. and Senior, C. (2008) 'Examining the influence of fame in the presence of beauty: an electrodermal "neuromarketing" study', Journal of Consumer Behavior, Vol. 341, No. 10, pp.331-341, doi:10.1002/cb.255.

44) Erk S., Kiefer M., Grothe J. o., Wunderlich A. P., Spitzer M., Walter H. Emotional context modulates subsequent memory effect. Neuroimage. 2003;18(2):439-447. doi: 10.1016/s1053-8119(02)00015-0. [PubMed] [CrossRef] [Google Scholar]

45) Bechara A., Damasio A. R. The somatic marker hypothesis: a neural theory of economic decision. Games and Economic Behavior. 2005;52(2):336-372. doi: 10.1016/j.geb.2004.06.010. [CrossRef] [Google Scholar]

46) 82. Camerer C., Loewenstein G., Prelec D. Neuroeconomics: how neuroscience can inform economics. Journal of Economic Literature. 2005;43(1):9-64. doi: 10.1257/0022051053737843. [CrossRef] [Google Scholar]

47) Kosslyn, S. M. (1999). If neuroimaging is the answer, what is the question?. Philosophical Transactions of the Royal Society of London. Series B: Biological Sciences, 354(1387), 1283- 1294.

48) Taher, N. (2006). Neuromarketing. New York: ICFAI University Press

49) Gang, D. J., Lin, W., Qi, Z., \& Yan, L. L. (2012, May). Neuromarketing: Marketing through Science. In Service Sciences (IJCSS),

50) Butler, M. J. (2008). Neuromarketing and the perception of knowledge. Journal of Consumer Behaviour, 7(4-5), 415-419 
51) Kenning, P., \& Linzmajer, M. (2011). Consumer neuroscience: an overview of an emerging discipline with implications for consumer policy. Journal für Verbraucherschutz und Lebensmittelsicherheit, 6(1), 111-125

52) Lee N, Broderick AJ, Chamberlain L (2007) What is 'neuromarketing'? A discussion and agenda for future research. Int J Psychophysiol 63(2): 199-204.

53) Simon H, Dolan RJ (1998) Price Customization. Marketing Management 7(3): 11-17.

54) Vanhuele $M$, Drèze $X$ (2002) Measuring the price knowledge shoppers bring to the store. Journal of Marketing 66(4): 72-85.

55) Evanschitzky H, Kenning P, Vogel V (2004) Consumer price knowledge in the German retail market. Journal of Product and Brand Management 13(6): 390-405.

56) Calvert GA, Brammer MJ (2012) Predicting consumer behaviour: Using novel mind-reading approaches. IEEE Pulse 3(3): 38-41.

57) Postma (2012) Anatomy of the Temptation. Neuromarketing - Neuromarketing successful to fit.

58) Ailawadi KL, Keller KL (2004) Understanding retail branding: Conceptual insights and research priorities. Journal of Retailing 80(4): 331-342.

59) Chandon P, Hutchinson JW, Bradlow ET, Young SH (2009) Does in-store marketing work? Effects of the number and position of shelf facings on brand attention and evaluation at the point of purchase. Journal of Marketing 73(6): 1-17.

60) Pieters R, Warlop L (1999) Visual attention during brand choice: The impact of time pressure and task motivation. International Journal of Research in Marketing 16(1): 1-16.

61) Plassmann H, Ramsøy TZ, Milosavljevic M (2012) Branding the brain: A critical review and outlook. Journal of Consumer Psychology 22(1): 18-36.

62) Dreze X, Hussherr FX (2003) Internet advertising: Is anybody watching? Journal of Interactive Marketing 17(4): 8-23.

63) Rangel A, Camerer C, Montague PR (2008) A framework for studying the neurobiology of value- based decision making. Nature Reviews Neuroscience 9(7): 545-556.

64) Plassmann H, Rams $\varnothing$ y TZ, Milosavljevic M (2012) Branding the brain: A critical review and outlook. J Consumer Psychol 22(1): 18-36.

65) Peelen MV, Li FF, Kastner S (2009) Neural mechanisms of rapid natural scene categorization in human visual cortex. Nature 460: 94-97.

66) Vohs KD, Schooler JW (2008) The value of believing in free will: Encouraging a belief in determinism increases cheating. Psychol Sci 19(6): 49-54.

67) Montague R (2008) Free will. Current Biology 18(4): 584-585.

68) Bechara A, Damasio AR (2005) The somatic marker hypothesis: A neural theory of economic decision. Games and Economic Behaviour 52(2): 336-372.

69) Kenning P, Linzmajer M (2011) Consumer neuroscience: An overview of an emerging discipline with implications for consumer policy. Journal für Verbraucherschutz und Lebensmittelsicherheit 6(1): 111-125.

70) Hubert M, Kenning P (2008) A current overview of consumer neuroscience. J Consumer Behav 7(4-5): 272-292.

71) McClure SM, Li J, Tomlin D, Cypert KS, Montague LM, et al. (2004) Neural correlates of behavioural preference for culturally familiar drinks. Neuron 44(2): 379-387.

72) Schaefer M, Berens $H$, Heinze $H$, Rotte M (2006) Neural correlates of culturally familiar brands of car manufacturers. Neuroimage 31(2): 861- 865.

73) Walter $\mathrm{H}$, Abler B, Ciaramidaro A, Erk S (2005) Motivating forces of human actions: Neuroimaging reward and social interaction. Brain Res Bull 67: 368-381.

74) Reimann M, Zaichkowsky J, Neuhaus C, Bender T, Weber B (2010) Aesthetic package design: A behavioral, neural and psychological investigation. J Consumer Psychol 20(4): 431-441.

75) Murphy E. R., Illes J., Reiner P. B. Neuroethics of neuromarketing. Journal of Consumer Behaviour. 2008;7(4-5):293-302. doi: 10.1002/cb.252. [CrossRef] [Google Scholar]

76) Ziegenfuss J. Neuromarketing: evolution of advertising or unethical use of medical technology. The Brownstone Journal. 2005;12 [Google Scholar]

77) Ruskin G. Commercial alert asks senate commerce committee to investigate neuromarketing. Commercial Alert. 2004:p. 30. [Google Scholar]

78) 409. Acuff D. Taking the guesswork out of responsible marketing. Young Consumers. 2005;6(4):68-71. doi: 10.1108/17473610510701331. [CrossRef] [Google Scholar] 
79) 410. Javor A., Koller M., Lee N., Chamberlain L., Ransmayr G. Neuromarketing and consumer neuroscience: contributions to neurology. BMC Neurology. 2013;13(1):p. 13. doi: 10.1186/1471-2377-13-13. [PMC free article] [PubMed] [CrossRef] [Google Scholar]

80) Senior C., Lee N. A manifesto for neuromarketing science. Journal of Consumer Behaviour. 2008;7(4-5):263-271. doi: 10.1002/cb.250. [CrossRef] [Google Scholar]

81) Eser Z., Isin F. B., Tolon M. Perceptions of marketing academics, neurologists, and marketing professionals about neuromarketing. Journal of Marketing Management. 2011;27(7-8):854-868. doi: 10.1080/02672571003719070. [CrossRef] [Google Scholar]

82) . Fugate D. L. Marketing services more effectively with neuromarketing research: a look into the future. Journal of Services Marketing. 2008;22(2):170-173. doi: 10.1108/08876040810862903. [CrossRef] [Google Scholar]

83) Murphy E. R., Illes J., Reiner P. B. Neuroethics of neuromarketing. Journal of Consumer Behaviour. 2008;7(4-5):293-302. doi: 10.1002/cb.252. [CrossRef] [Google Scholar]

84) Javor A., Koller M., Lee N., Chamberlain L., Ransmayr G. Neuromarketing and consumer neuroscience: contributions to neurology. BMC Neurology. 2013;13(1):p. 13. doi: 10.1186/1471-2377-13-13. [PMC free article] [PubMed] [CrossRef] [Google Scholar]

85) Murphy E. R., Illes J., Reiner P. B. Neuroethics of neuromarketing. Journal of Consumer Behaviour. 2008;7(4-5):293-302. doi: 10.1002/cb.252. [CrossRef] [Google Scholar]

86) Lee N., Broderick A. J., Chamberlain L. What is 'neuromarketing'? A discussion and agenda for future research. International Journal of Psychophysiology. 2007;63(2):199-204. doi: 10.1016/j.ijpsycho.2006.03.007. [PubMed] [CrossRef] [Google Scholar]

87) Fisher C. E., Chin L., Klitzman R. Defining neuromarketing: practices and professional challenges. Harvard Review of Psychiatry. 2010;18(4):230-237. doi: 10.3109/10673229.2010.496623. [PMC free article] [PubMed] [CrossRef] [Google Scholar]

88) Fugate D. L. Neuromarketing: a layman's look at neuroscience and its potential application to marketing practice. Journal of Consumer Marketing. 2007;24(7):385-394. doi: 10.1108/07363760710834807. [CrossRef] [Google Scholar]

89) Murphy E. R., Illes J., Reiner P. B. Neuroethics of neuromarketing. Journal of Consumer Behaviour. 2008;7(4-5):293-302. doi: 10.1002/cb.252. [CrossRef] [Google Scholar]

90) Huisingh, D. (2012) 'Invitation to authors to prepare \& submit, comprehensive/integrative review articles', Journal of Cleaner Production, July, Vols. 29-30, p.290 [online] https://doi.org/10.1016/j.jclepro.2012.02.006.

91) Lage Jr., M. and Godinho Filho, M. (2010) 'Variations of the kanban system: literature review and classification', International Journal of Production Economics, Vol. 125, No. 1, pp.13-21, doi:10.1016/j.ijpe.2010.01.009

92) Solnais, C., Perez, J.A., Fernandez, J.S. and Abela, J.A. (2013) 'The contribution of neuroscience to consumer research: a conceptual framework and empirical review', Journal of Economic Psychology, Vol. 36, No. 6, pp.68-81, doi:10.1016/j.joep.2013.02.011.

93) Venkatraman, V., Clithero, J.A., Fitzsimons, G.J. and Huettel, S.A. (2012) 'New scanner data for brand marketers: how neuroscience can help better understand differences in brand preferences', Journal of Consumer Psychology, Vol. 22, No. 1, pp.143-153, doi:10.1016/ j.jcps.2011.11.008.

94) Ohme, R. and Matukin, M. (2012) 'A small frog that makes a big difference: brain wave testing of TV advertisements', IEEE Pulse, Vol. 3, No. 3, pp.28-33, doi:10.1109/MPUL.2012.2189169

95) Khushaba, R.N., Wiseb, C., Kodagodaa, S., Louviereb, J., Kahnc, E. and Townsend, C. (2013) 'Consumer neuroscience: assessing the brain response to marketing stimuli using electroencephalogram (EEG) and eye tracking', Expert Systems with Applications, Vol. 40, No. 9, pp.3803-3812, doi:10.1016/j.eswa.2012.12.095.

96) Babiloni, F. (2012) 'Consumer neuroscience - a new area of study for biomedical engineers', IEEE Pulse, Vol. 21, No. 6, pp.21-23, doi:10.1109/MPUL.2012.2189166

97) Fisher, C.E., Chin, L. and Klitzman, R. (2010) 'Defining neuromarketing: practices and professional challenges', Harvard Review of Psychiatry, Vol. 18, No. 4, pp.230-237, doi:10.3109/10673229.2010.496623.

98) Kenning, P. and Linzmajer, M. (2011) 'Consumer neuroscience: an overview of an emerging discipline with implications for consumer policy', Journal für Verbraucherschutz und Lebensmittelsicherheit, Vol. 6, No. 1, pp.111-125, doi:10.1007/s00003-010-0652-5.

99) Orzan, G., Zara, I.A. and Purcarea, V.L. (2012) 'Neuromarketing techniques in pharmaceutical drugs advertising. A discussion and agenda for future research', Journal of Medicine and Life, Vol. 5, No. 4, pp.428-432. 